\title{
Redefining seed dormancy: an attempt to integrate physiology and ecology
}

\author{
L. M. VLEESHOUWERS, H. J. BOUWMEESTER* and C. M. KARSSEN† \\ Wageningen Agricultural University, Department of Theoretical Production Ecology, PO Box 430,6700 AK \\ Wageningen, *Research Institute for Agrobiology and Soil Fertility, PO Box 14,6700 AA Wageningen and \\ $\dagger$ Wageningen Agricultural University, Department of Plant Physiology, Arboretumlaan 4, 6703 BD Wageningen, \\ the Netherlands
}

\begin{abstract}
Summary
1 The paper reviews the literature on seed dormancy, with special regard to inconsistencies in terms and definitions used. It presents a concept of seed dormancy in which physiology and ecology are integrated. Its aim is to increase the understanding of seed dormancy and germination, and to help defining ecological research questions. 2 It is claimed that seed dormancy should not be identified with the absence of germination. Seed dormancy should rather be defined as a characteristic, the degree of which determines the range of conditions in which a seed is able to germinate. Dormancy varies on a continuous scale, which is visualized by continuous changes in the range of conditions suitable for germination. If the conditions required by the seed are met by its environment, the seed will germinate.

3 The concept of dormancy that is described in the paper is partly based on a physiological model for the regulation of dormancy and the stimulation of germination. In this model dormancy is related to the amount of a hypothetical phytochrome receptor in the seed.

$4 \mathrm{It}$ is argued that the process of dormancy release should be clearly distinguished from the germination process itself. It is stated that as yet only temperature has been shown to alter the degree of dormancy in seeds. Factors like light and nitrate are often indispensable for germination, but only by promoting the germination process itself, not by mitigating the requirements for germination.

5 It is suggested that seed dormancy prevents germination when conditions are favourable for germination, at a time of the year when it can be expected that the plant originating from the seed will not survive and produce offspring.

6 It is concluded that dormancy should not be regarded as inactivity of seeds. At any degree of dormancy, seeds continuously react to their environment by adjusting their level of dormancy to the changing environment.
\end{abstract}

Keywords: germination, seed ecology, seed physiology, physiological dormancy, seed bank

Journal of Ecology (1995) 83, 1031-1037

'I watched the moths fluttering among the heath and harebells; listened to the soft wind breathing through the grass; and wondered how anyone could ever imagine unquiet slumbers, for the sleepers in that quiet earth.'

Emily Brontë, Wuthering Heights

\section{Introduction}

In the literature, there is no unanimity about the defi1031 dormancy. The statement made by Hobson (1981), that there may be as many definitions of dormancy as there are investigators concerned with the subject, can rightly be applied to the specific case of dormancy in seeds. This variety of ideas about dormancy is reflected in the number of classifications of dormancy employed by various authorities, as shown by Bewley \& Black (1982).

Therefore, it is surprising that dormancy is not seen 
as a controversial subject. For example, in the book

Seed dormancy
'Seeds: the ecology of regeneration in plant communities' (Fenner 1992) seed dormancy is dealt with in four separate chapters (Murdoch \& Ellis 1992; Pons 1992; Probert 1992; Karssen \& Hilhorst 1992), but none of the authors seeks to oppose his view against the others'. Nevertheless, they express different views on dormancy, between which there is friction, and sometimes plain contradiction. The fact that these contrasts are not stated explicitly in the literature may have an adverse effect on communication between researchers and on the understanding of each other's results and conclusions. This may lead to situations where scientists pose inaccurate research questions and set up defective experiments.

In this review we explain our position in the nondeclared debate on dormancy, particularly in regard to the definition of dormancy, the classification of dormancy, the distinction between dormancy and germination, and the significance of seed dormancy in the life-cycle of plants. In addition, we will indicate the way in which our view is based on recently developed ideas in seed physiology. We believe that the use of a physiologically sound concept of dormancy may lead to a better definition of ecological research questions concerning dormancy and germination. We do not claim that the concept of seed dormancy we discuss in this paper is the only one possible, but we do claim that it is coherent, and that it has enhanced our understanding of many observations on seed dormancy and germination.

We confine ourselves to those forms of dormancy named physiological dormancy by Baskin \& Baskin (1989), since this is the most frequently occurring type of dormancy in seed banks in temperate regions, and do therefore not consider dormancy caused by a hard seed coat nor by underdevelopment of the embryo.

\section{Definition and classification of dormancy}

Harper (1959) distinguished two categories among plants living in a community: those which are growing and those which are dormant. This definition of dormancy implies that, according to Harper, seeds are dormant when they are not germinating. Harper recognized three types of seed dormancy: 'some seeds are born dormant (innate), some achieve dormancy (induced) and some have dormancy thrust upon them (enforced)'.

Many authors have adopted the essence of Harper's ideas. They have identified seed dormancy with the absence of a germination response, and have taken over his classification of dormancy (e.g. Murdoch \& Ellis 1992). In our opinion, however, the phenomenon that was classified by Harper should be called the seeds' inability to germinate, instead of the seeds' dormancy. There is a clear distinction between these two phenomena, as we will illustrate later on. Moreover, in his classification Harper did not make a dis- tinct separation between the different causes for which a viable seed is unable to germinate. The causes he mentions are located both in the seed and in its environment, and are related to both dormancy and germination. We think that a sound concept of dormancy should clearly separate the internal and external factors that interact in seed germination. We reserve the term dormancy for a block or blocks within the seed that prevent germination, and distinguish it from the absence of factors required to evoke germination.

A classical notion of dormancy, which can be regarded as an elaboration of Harper's idea, is 'temporary failure of a viable seed to germinate, after a specified length of time, in a particular set of environmental conditions that later evoke germination when the restrictive state has been terminated by either natural or artificial means' (Simpson 1990). Vegis (1964) considered that changes in the dormancy of seeds involve changes in their temperature requirements for germination. As dormancy is induced, the range of temperatures over which germination can proceed narrows, until germination is no longer possible at any temperature, and full dormancy is reached. As dormancy is broken, the temperature range widens, until it is maximal. This implies that the dormancy of a seed is not an all-or-nothing property (cf. Baskin \& Baskin 1985). However, a seed's 'failure to germinate in a particular set of environmental conditions' is an all-or-nothing property.

If one equates dormancy with failure of germination, Vegis' theory would imply that, except for seeds that are fully dormant, the dormancy of seeds kept at a temperature outside the range required for germination can be relieved by transferring them to a temperature inside this range. This view is shared by Bewley \& Black (1982), who stated that dormancy may vary with external conditions, usually of temperature. On the other hand, dormancy is supposed to be an adaptive trait (e.g. Simpson 1990). This implies that dormancy should not be a measure of the external conditions a seed is currently exposed to, but be a characteristic of the seed. We believe that these inconsistencies result from an inaccurate definition of dormancy. Firstly, dormancy should be able to have any value between all and nothing, and, secondly, it should be a seed trait (cf. Gordon 1973).

Karssen (1982) emphasized that seasonal periodicity in the field-emergence of annuals is the combined result of seasonal periodicity in the field temperature and seasonal periodicity in the width of the range of temperatures suited for germination. Germination in the field is restricted to the period when the field temperature and the temperature range over which germination can proceed overlap (Fig. 1). Dormancy is only related to the width of the temperature range for germination, not to the question whether or not the current temperature is inside this range. Derkx \& Karssen (1993a) showed that in Sisymbrium officinale 
L.M. Vleeshouwers,

H.J. Bouwmeester \& C.M. Karssen

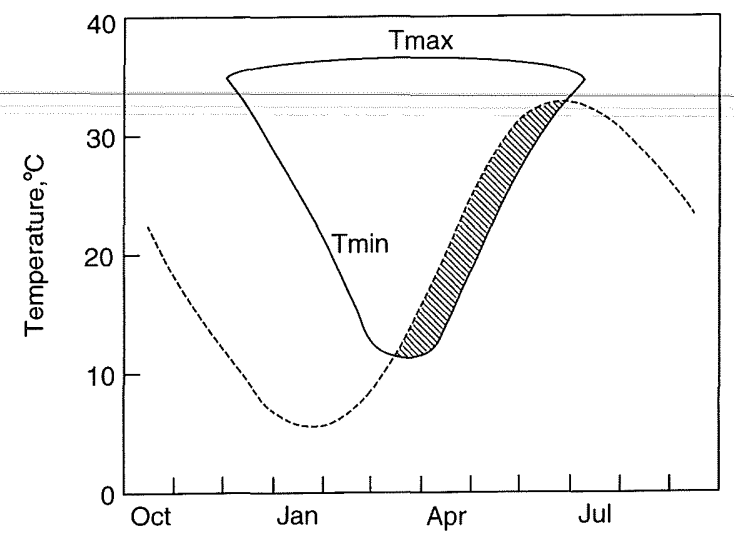

Fig. 1 Widening and narrowing of the temperature range of germination of a summer annual in relation to the temperature in the habitat during the seasons. The broken line indicates the mean daily temperature in the field. Solid lines indicate maximum $\left(T_{m u x}\right)$ and minimum $\left(T_{m i n}\right)$ temperature for germination. In the hatched area the actual and required temperatures overlap. (Adapted from Karssen 1982.)

changes in dormancy not only comprise changes in temperature requirements for germination, but also in its requirements for nitrate and light. Sensitivity to light and nitrate, both necessary stimuli for the germination of this species, increased when dormancy was broken and decreased when dormancy was induced.

Generalizing the concept of Karssen (1982), which is solely based on one factor, temperature, one may say that germination occurs when internal requirements and external factors meet. Dormancy is only related to the requirements for germination, not to the question whether or not these requirements are met in a particular environment. This is the reason why we oppose Harper's (1959) concept of dormancy. Standstill of plant growth, which he calls dormancy, only indicates that the requirements for growth are not met.

We propose a different definition of seed dormancy: dormancy is a seed characteristic, the degree of which defines what conditions should be met to make the seed germinate.

The wider the range of conditions at which a seed is able to germinate, the smaller its degree of dormancy (cf. Hilhorst 1993). One could regard dormancy as the seed's fastidiousness about the germination conditions it requires, whereas germination is the seed's response to an overlap of the environmental conditions and the germination requirements, defined by the degree of dormancy (Fig. 2)

When doing experiments, one should realize that because of the different nature of germination and dormancy, the result of a germination test can only be an approximate representation of the dormancy state of seeds. This is especially true for a single seed. Whether or not the seed germinates in a germination test cannot be a measure of its dormancy. However, for a large seed population germination tests over a

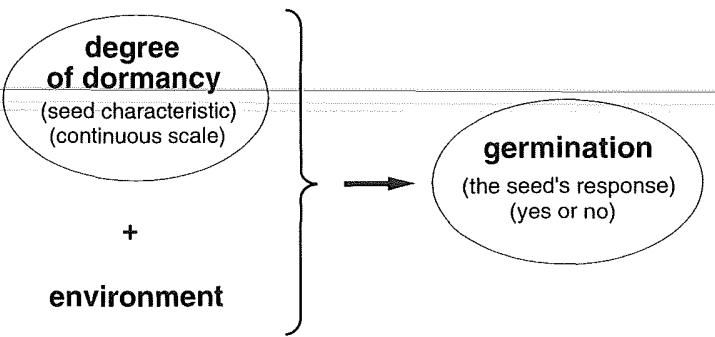

Fig. 2 Diagrammatic representation of the interaction of seed and environment in the process of germination. The degree of dormancy defines the germination requirements of the seed. If these requirements are met by the environment the seed will germinate, if they are not the seed will fail to germinate. It should be realized that the degree of dormancy of a seed at a certain moment is influenced by the environmental conditions it has experienced during its existence back to the conditions in which it has ripened at the mother plant.

range of environmental conditions can give a satisfactory impression of the degree of dormancy.

We will not try to devise a new classification of dormancy. We think the existing classification in primary and secondary dormancy, introduced by Crocker (1916), adequate. Primary dormancy is the dormancy state of the freshly shed seed. When primary dormancy has been relieved and suitable conditions are present, the seed germinates. If suitable conditions are not present, and germination does not occur, secondary dormancy may develop. Secondary dormancy of buried seeds can be relieved and reinduced during many successive seasons.

\section{Factors affecting changes in dormancy and the actual germination process}

The distinction between dormancy and germination that we advocate is not only based on theoretical considerations. It is shown experimentally that the processes of dormancy change and germination are regulated by different environmental factors. Besides, it is shown that both processes are regulated by temperature, but in a different way. An unfortunate circumstance is that it is, as yet, impossible to measure the dormancy state of a seed directly. One can only get an impression of the seed's dormancy by trying to make it germinate. This has led to the situation that many researchers do not make a clear distinction between changes in dormancy and the process of germination. Vincent \& Roberts (1977), and Bewley \& Black (1982), for example, call light and nitrate at one time factors that affect dormancy, at another time factors that promote germination. We do distinguish between dormancy release and stimulation of germination, and also between induction of dormancy and inhibition of germination.

Generally, changes in dormancy are investigated by storing seeds in imbibed conditions in an environment that allows seed survival but prevents ger- 
mination (Baskin \& Baskin 1985). At regular inter-

vals, samples of the stored seeds are taken and their germination is tested in a range of conditions. If the range of conditions allowing germination changes in the course of time, one can conclude that the storage conditions affected seed dormancy. Dormancy relieving factors will cause a widening of the range of conditions that allow germination, and dormancy inducing factors will cause a narrowing of this range. Factors that do not change the seeds' fastidiousness as to the germination conditions, but are at the same time indispensable to obtain a germination response, are germination inducing factors.

Bouwmeester \& Karssen (1992) buried seeds of Polygonum persicaria in the field at a depth of $10 \mathrm{~cm}$. At regular intervals over a period of three years, they exhumed samples of these seeds and tested them for germination over a range of temperatures. They showed that seasonal changes in the width of the temperature range over which exhumed seeds germinate (i.e. seasonal changes in dormancy) could be simulated by using only the soil temperature as an explanatory factor (Fig. 3). The changes in dormancy did not correlate with seasonal changes in soil moisture and soil nitrate content. The authors concluded that soil moisture and nitrate content do not influence changes in dormancy. Since the seeds were buried in continuous darkness, their conclusion can be extended to the factor light. However, nitrate, soil moisture and light are factors that strongly influence germination (e.g. Vincent \& Roberts 1977).

A complicating factor is that temperature has a dual role. It regulates the seasonal changes in dormancy, but also germination (e.g. Bouwmeester \& Karssen 1992, 1993). The temperature requirements of both processes are, however, quite different. Dormancy of Polygonum persicaria can be broken at temperatures that will never allow germination of this species (Fig. 3, December 1986 until March 1987).
Conversely, at the end of spring temperatures favour germination, but also induce dormancy (Fig. 3). If, at this time, the light-requiring seeds of Polygonum persicaria remain buried in the soil in darkness, germination is prevented by lack of light, and the prevailing temperatures will cause induction of dormancy. However, if the soil is disturbed, the seeds may be irradiated by daylight, and germination may take place at the prevailing temperatures. In this case, germination and induction of dormancy occur simultaneously. However, they do not really compete, because full induction of dormancy in buried seeds takes several months, while germination is completed in a few days.

Derkx \& Karssen (1993a) showed that when Sisymbrium officinale seeds are buried in darkness germination is prevented. However, the temperature they are exposed to regulates the changes in the requirements for light, nitrate and temperature for subsequent germination (i.e. regulates dormancy). Changes in dormancy occur in spite of continuous darkness and are not correlated with changes in endogenous nitrate content (Derkx \& Karssen 1993a). From experiments in which Sisymbrium officinale seeds were incubated in darkness, Derkx et al. (1993b) concluded that changes in dormancy are not related to changes in respiratory activity. They reported that when the seeds are irradiated by red light, $\mathrm{O}_{2}$ uptake starts to rise immediately as an early indication of the germination process having started. Consequently, Derkx \& Karssen (1993a) called the effect of irradiation stimulation of germination instead of relief of dormancy. Generally, light requirement by seeds is considered to be a form of dormancy. This corresponds to our view. The effect of irradiation is usually called breakage of dormancy. We prefer to call this effect induction of germination. We think it consequent to describe as 'dormancy breaking' only those factors that mitigate the requirements for ger-

Fig. 3 Simulation of seasonal changes in the range of temperatures over which at least $50 \%$ of exhumed Polygonum persicaria seeds germinate. Solid lines represent maximum and minimum temperature required for $50 \%$ germination in water, calculated according to a descriptive model based on temperature derived parameters. The dotted line indicates air temperature at $1.50 \mathrm{~m}$. Hatched areas indicate overlap of field temperature and germination temperature range. Arrows indicate the time when germination in Petri dishes outdoors actually increased above $(\uparrow)$ or decreased below $(\downarrow)$ $50 \%$. (Adapted from Bouwmeester \& Karssen 1992.)

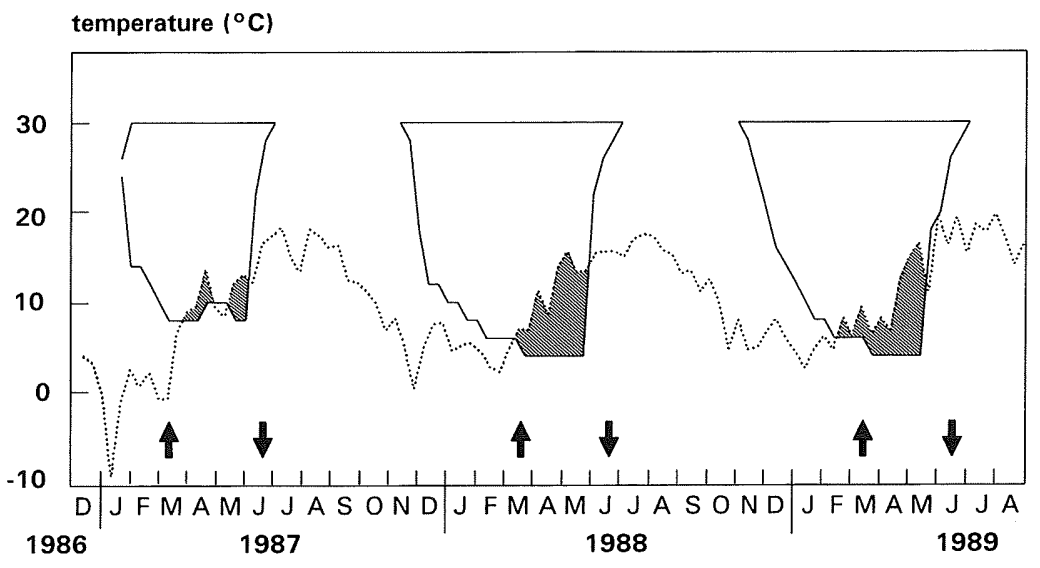


mination, like a low winter temperature, which,

L.M. Vleeshouwers,

H.J. Bouwmeester \& C.M. Karssen

among other things, decreases the light intensity needed for germination of Sisymbrium officinale (Derkx \& Karssen 1993a).
Another factor, the effect of which should be reconsidered, is fluctuation of temperature. Alternating temperatures are widely thought to be dormancy relieving (e.g. Bewley \& Black 1982), but recent unpublished results of Bouwmeester indicate that in seeds of Sisymbrium officinale a pretreatment at alternating temperatures in darkness hampers subsequent germination at a constant temperature after irradiation. Alternating temperatures enhance germination of Sisymbrium officinale only when applied after irradiation of the seeds. Apparently, alternating temperatures cause induction of dormancy, but promote the germination process, once the seed has been irradiated.

\section{Some considerations about the role of dormancy in the life-cycle of plants}

Annual cycles in which dormancy is relieved and induced occur in buried seeds of many annual species throughout the lifetime of the seeds. The separation of dormancy from germination has shed new light on the role of seed dormancy within the life-cycle of plants. In our view, dormancy is not so much a device for surviving prolonged periods of unfavourable conditions, which is often claimed, as a device for surviving short periods of favourable conditions. In unfavourable conditions the lack of germination-stimulating factors will prevent germination, and the seed will survive ungerminated in the soil, independent of its dormancy state. Dormancy prevents germination in periods of conditions that are favourable for germination, at a time of the year when it can be expected that the plant that originates from the seed will not survive and produce offspring.

In summer annuals, for example, changes in dormancy enable seeds to germinate in spring, but prevent germination in autumn, although the prevailing conditions in the field (light, nitrate, temperature, soil moisture) may be quite similar in both seasons. Germination in autumn, however, would not allow the completion of the life-cycle of the plant before winter, and has to be avoided. This was also acknowledged by Simpson (1990) who stated that dormancy is an adaptive trait that optimizes the distribution of germination over time within a population of seeds. The timing of germination in the field is the combined effect of changes in dormancy and changes in environmental conditions.

Another example is given by Ter Borg (1987) who showed that seeds of Rhinanthus species occurring in a lowland habitat need a longer period of chilling to relieve their dormancy than seeds of Rhinanthus species occurring in a mountain habitat, where winter is even longer. In the lowland habitat, however, low

winter temperatures are generally interrupted by warmer spells, during which a high degree of dormancy is required to prevent germination. In the mountain habitat the soil is covered by snow during winter and this prevents the seeds from germinating too early, which makes an internal dormancy mechanism superfluous.

We do not agree with the claim that dormancy also optimizes the distribution of germination in space (e.g. Pons 1989, 1992). Dormancy is not affected by the environmental factors by which seeds sense that their position in the soil is suitable for germination. The main factors that allow seeds to detect their depth of burial and the absence of competitors in their proximity are alternating temperatures, nitrate, light quantity and light quality, all of them stimulating germination.

\section{A hypothetical physiological dormancy model}

Hilhorst (1993) presented a hypothetical physiological model for the regulation of secondary dormancy and the stimulation of germination (Fig. 4) (see also Van Loon \& Bruinsma 1992). As yet there is only circumstantial evidence for the mechanism that is hypothesized in this model. The merit of the model is that it structures and integrates a large number of observations on dormancy and germination in a concise and comprehensible way. It corresponds to the concept of dormancy that we discussed in the

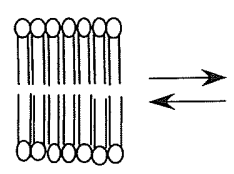

a

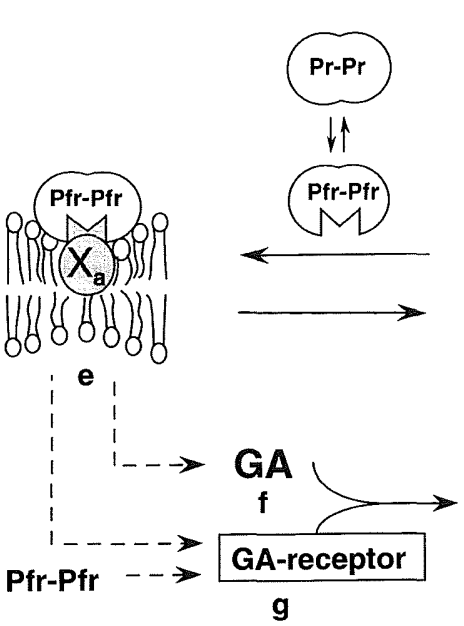

g

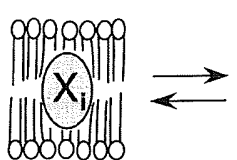

b

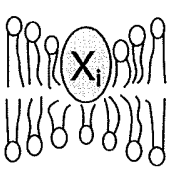

c
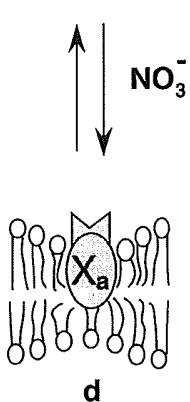

d

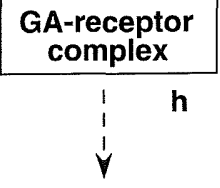

Germination

Fig. 4 Physiological model for relief and induction of dormancy, and stimulation of germination in light-requiring seeds. The phytochrome-receptor $\mathrm{X}$ is located in the plasma membrane. $X_{i}$ denotes the inactive receptor, $X_{u}$ the activated receptor. Pr-Pr: inactive phytochrome, Pfr-Pfr: activated phytochrome, GA: gibberellins. Letters in the figure refer to explanation in the text. (Adapted from Hilhorst 1993.) 
In many species light is the primary inducer of germination. Irradiation by daylight converts the inactive form of the pigment phytochrome into the active form. In the model the response to light is supposed to be effected by an interaction between active phytochrome and its tentative receptor $\mathrm{X}$. This receptor is assumed to be located in the plasma membrane. Hilhorst (1993) hypothesizes that modulation of the number of molecules of receptor $\mathrm{X}$ accounts for changes in dormancy.

We will explain the model for the case of a summer annual. Generally, in summer annuals low (winter) temperatures relieve dormancy, while high (summer) temperatures induce dormancy (Karssen 1982). In the state of maximal dormancy the receptor is absent (Fig. 4a). At low temperatures, receptors are synthesized (Fig. 4b). This is the actual dormancy relieving process. At high temperatures, receptors are degraded. This is the actual dormancy inducing process.

The remaining part of the model concerns the stimulation of germination. Hilhorst (1993) assumes that a rise in temperature inducing an increase in fluidity of the membrane may be necessary to enable the receptor to move to the membrane surface and become exposed (Fig. 4c). The exposed receptor is activated by interaction with nitrate (Fig. 4 d). The activated receptor can now bind its agonist phytochrome, which is activated by irradiation of the seed (Fig. 4e). The phytochrome-receptor complex generates a signal that leads to synthesis of gibberellins (GA) (Fig. 4f). In addition, either activated phytochrome or the phytochrome-receptor complex enhances the sensitivity of receptors to GA (Fig. $4 \mathrm{~g}$ ). Finally, a signal from the GA-receptor complex (Fig. 4 h) leads to germination.

In this biochemical model, dormancy is directly related to the amount of phytochrome-receptor X. The amount of $X$ determines the seed's responsiveness to light and nitrate, and also the width of the temperature range for germination (Vleeshouwers \& Bouwmeester 1993). The only factor effecting a change in the amount of $X$, and thus changing the seed's degree of dormancy, is temperature. All factors that are required to realize germination of a seed which has a sufficient amount of $\mathrm{X}$ are germination stimuli. The distinction between dormancy relieving and germination inducing factors that was made earlier in this paper is therefore in agreement with this physiological model.

\section{Primary and secondary dormancy}

Although the classification into primary and secondary dormancy was originally based on the timing of the dormancy (Crocker 1916; Karssen 1982), it also seems to have a physiological background and
Sisymbrium officinale seeds, sensitivity to GA gradually increases. However, sensitivity to GA remains at a high level when secondary dormancy is induced and subsequently relieved. This implies that the relief of primary dormancy is physiologically different from the relief of secondary dormancy. On the other hand, in Sisymbrium officinale both types of dormancy are relieved by the same environmental factors (Karssen 1982).

Bouwmeester \& Karssen (1993) reported that fresh Sisymbrium officinale seeds or seeds that were buried for a limited time (being in a state of primary dormancy) germinate better at high temperatures than at low temperatures, whereas seeds exhumed after more than five months' burial (being in a state of secondary dormancy) germinate better at low temperatures than at high temperatures. This implies that both types of dormancy may cause a different germination response. We suggest that this difference in germination response results from a change of the process controlling germination, which shifts from the binding of GA to its receptor in case of primary dormancy to the binding of phytochrome to its receptor in case of secondary dormancy.

In any case we conclude that one should be cautious when extrapolating germination results that were obtained with fresh seeds in order to predict germination of seeds that are buried in the seed bank.

\section{Unquiet slumbers, for the sleepers in that quiet earth}

Simpson (1990) mentioned that the English word 'dormancy' is derived from the Latin dormire (to sleep) and is defined in the Concise Oxford Dictionary as 'lying inactive in sleep'. In agreement with this definition, Ricklefs (1990) stated that by their dormancy mechanism plants ride out unfavourable conditions and await better ones before resuming an active and interactive state. However, from the foregoing, one may understand that seeds are far from passively asleep during their annual dormancy cycle. Throughout the seasons seeds continuously sense their environment and adjust their level of dormancy to the changing environment. Thus, they increase the chance of completing their life-cycle successfully, once they have germinated. This sensing of the environment is independent of their degree of dormancy. Seeds are rather 'lying active in sleep' or 'watchfully asleep'.

\section{Acknowledgements}

We thank Dr H. W. M. Hilhorst and Dr M. P. M. Derkx for their contribution to the numerous discussions on which we based this paper to a large extent. 
Baskin, J.M. \& Baskin, C.C. (1985) The-annual dormancy cycle in buried weed seeds: A continuum. BioScience, 35, 492-498.

\& C.M. Karssen
Baskin, J.M. \& Baskin, C.C. (1989) Physiology of dormancy and germination in relation to seed bank ecology. Ecology of Soil Seed Banks (eds M.A. Leck, V.T. Parker \& R.L. Simpson), pp. 53-66. Academic Press, San Diego.

Bewley, J.D. \& Black, M. (1982) Physiology and Biochemistry of Seeds, Vol. 2. Viability, Dormancy, and Environmental Control. Springer-Verlag, Berlin.

Bouwmeester, H.J. \& Karssen, C.M. (1992) The dual role of temperature in the regulation of the seasonal changes in dormancy and germination of seeds of Polygonum persicaria L. Oecologia, 90, 88-94.

Bouwmeester, H.J. \& Karssen, C.M. (1993) Annual changes in dormancy and germination in seeds of Sisymbrium officinale (L.) Scop. New Phytologist, 124, 179-191.

Crocker, W. (1916) Mechanics of dormancy in seeds. American Journal of Botany, 3, 99-120.

Derkx, M.P.M. \& Karssen, C.M. (1993a) Changing sensitivity to light and nitrate but not to gibberellins regulates seasonal dormancy patterns in Sisymbrium officinale seeds. Plant, Cell and Environment, 16, 469-479.

Derkx, M.P.M., Smidt, W.J., Van der Plas, L.H.W. \& Karssen, C.M. (1993b) Changes in dormancy of Sisymbrium officinale seeds do not depend on changes in respiratory activity. Physiologia Plantarum, 89, 707-718.

Gordon, A.G. (1973) The rate of germination. Seed Ecology (ed.W. Heydecker), pp. 391-410. Butterworths, London.

Harper, J.L. (1959) The ecological significance of dormancy and its importance in weed control. Proceedings of the IVth International Congress of Crop Protection, Hamburg, September 1957, Vol. 1, pp. 415-420. Selbstverlag des IV. Internationalen PflanzenschutzKongresses, Braunschweig.

Hilhorst, H.W.M. (1993) New aspects of seed dormancy. Proceedings of the Fourth International Workshop on Seeds. Basic and Applied Aspects of Seed Biology. Angers, France, 20-24 July 1992, Vol. 2 (eds D. Côme \& F. Corbineau), pp. 571-579. Université Pierre et Marie Curie, Paris.

Hobson, G.E. (1981) Changes in mitochondrial composition and behaviour in relation to dormancy. Annals of Applied Biology, 98, 541-544.

Karssen, C.M. (1982) Seasonal patterns of dormancy in weed seeds. The Physiology and Biochemistry of Seed Khan), pp. 243-270. Elsevier Biomedical Press, Amsterdam.

Karssen, C.M. \& Hilhorst, H.W.M. (1992) Effect of chemical environment on seed germination. Seeds. The Ecology of Regeneration in Plant Communities (ed. M. Fenner), pp. 327-348. C.A.B International, Wallingford.

Murdoch, A.J. \& Ellis, R.H. (1992) Longevity, viability and dormancy. Seeds. The Ecology of Regeneration in Plant Communities (ed. M. Fenner), pp. 193-229. C·A·B International, Wallingford.

Pons, T.L. (1989) Breaking of seed dormancy by nitrate as a gap detection mechanism. Annals of Botany, 63, 139144.

Pons, T.L. (1992) Seed responses to light. Seeds. The Ecology of Regeneration in Plant Communities (ed. M. Fenner), pp. 259-284. C.A.B International, Wallingford.

Probert, R.J. (1992) The role of temperature in germination ecophysiology. Seeds. the Ecology of Regeneration in Plant Communities (ed. M. Fenner), pp. 285-325. C·A·B International, Wallingford.

Ricklefs, R.E. (1990) Ecology. W. H. Freeman and Company, New York.

Simpson, G.M. (1990) Seed Dormancy in Grasses. Cambridge University Press, Cambridge.

Ter Borg, S.J. (1987) Qualitative and quantitative aspects of the interaction between Rhinanthus and Orobanche species and their hosts. Parasitic Flowering Plants (eds H. C. Weber \& W. Forstreuter), pp. 109-120. PhilippsUniversität, Marburg.

Van Loon, L.C. \& Bruinsma, J. (1992) The new plant physiology - molecular approaches to studying hormonal regulation of plant development. Acta Botanica Neerlandica, 41, 1-23.

Vegis, A. (1964) Dormancy in higher plants. Annual Review of Plant Physiology, 15, 185-224.

Vincent, E.M. \& Roberts, E.H. (1977) The interaction of light, nitrate and alternating temperature in promoting the germination of dormant seeds of common weed species. Seed Science and Technology, 5, 659-670.

Vleeshouwers, L.M. \& Bouwmeester, H.J. (1993) A simulation model for the dormancy cycle of weed seeds in the seed bank. Proceedings of the 8th EWRS Symposium 'Quantitative approaches in weed and herbicide research and their practical application', Vol. 2, pp. 593-600.

Received 26 August 1994

revised version accepted 22 February 1995 
